\title{
Primary Molecular Disorders and Secondary Biological Adaptations in Bartter Syndrome
}

\author{
Georges Deschênes ${ }^{1,2}$ and Marc Fila ${ }^{1,2}$ \\ ${ }^{1}$ Pediatric Nephrology Unit, Hôpital Robert-Debré, 48 Bd Sérurier, 75019 Paris, France \\ ${ }^{2}$ Faculté de Médecine Xavier Bichat, University Paris 7, 16 rue Henri Huchard, 75018 Paris, France
}

Correspondence should be addressed to Georges Deschênes, georges.deschenes@rdb.aphp.fr

Received 19 April 2011; Accepted 1 June 2011

Academic Editor: Franz Schaefer

Copyright (C) 2011 G. Deschênes and M. Fila. This is an open access article distributed under the Creative Commons Attribution License, which permits unrestricted use, distribution, and reproduction in any medium, provided the original work is properly cited.

\begin{abstract}
Bartter syndrome is a hereditary disorder that has been characterized by the association of hypokalemia, alkalosis, and the hypertrophy of the juxtaglomerular complex with secondary hyperaldosteronism and normal blood pressure. By contrast, the genetic causes of Bartter syndrome primarily affect molecular structures directly involved in the sodium reabsorption at the level of the Henle loop. The ensuing urinary sodium wasting and chronic sodium depletion are responsible for the contraction of the extracellular volume, the activation of the renin-aldosterone axis, the secretion of prostaglandins, and the biological adaptations of downstream tubular segments, meaning the distal convoluted tubule and the collecting duct. These secondary biological adaptations lead to hypokalemia and alkalosis, illustrating a close integration of the solutes regulation in the tubular structures.
\end{abstract}

\section{Introduction}

Bartter syndrome is a hereditary disorder that has been characterized by the association of hypokalemia, alkalosis and the hypertrophy of the juxtaglomerular complex with secondary hyperaldosteronism and normal blood pressure [1]. By contrast, the genetic causes of Bartter syndrome primarily affect molecular structures directly involved in the sodium reabsorption at the level of the Henle loop (see the functional segmentation of sodium reabsorption in Figure 1 and $[2,3]$. The ensuing urinary sodium wasting and chronic sodium depletion are responsible for the contraction of the extracellular volume, the activation of the renin-aldosterone axis, the secretion of prostaglandins, and the biological adaptations of downstream tubular segments, meaning the distal convoluted tubule and the collecting duct. These secondary biological adaptations lead to hypokalemia and alkalosis, illustrating a close integration of the solutes regulation in the tubular structures.

\section{Primary Molecular Defects and Direct Consequences}

Genome alterations leading to the Bartter syndrome affect the genes encoding different molecules involved in the sodium reabsorption at the level of the large ascending limb of the Henle loop (Figure 2). Sodium-Potassium-Chloride Cotransporter (NKCC2, gene SLC12A1) is responsible for Bartter type I, the inwardly rectified potassium channel (ROMK or rectifying outer medullary potassium channel, gene KCNJ1), for Bartter type II, the chloride channel $\mathrm{Kb}$ (ClCKb, gene CLCNKB; ) for Bartter type III, the barttin (gene BSND) for Bartter type IV [3]. A complete deletion of $C L C N K B$ gene with additional alterations of the $C l C K-A$ gene leads to a severe form of Bartter syndrome similar to Bartter syndrome type IV $[4,5]$. A biological phenotype of Bartter syndrome has also been reported in different damages of molecular structures that directly or indirectly affect sodium reabsorption in the Henle loop: the calcium-sensing 
receptor (CaSR, activating mutation $\mathrm{L} 125 \mathrm{P}$ ) that mainly leads to hypocalcemia and hypercalciuria, sometimes referred as type V Bartter syndrome [6], the Chloride channel5 (ClC5) [7], and the cystinosin [8]. Gitelman syndrome, due to the alteration of the SLC12A3 gene that encodes the Sodium chloride cotransporter in the distal convolution, is also marked by sodium wasting, hyperreninism, hyperaldosteronisme,and hypochloremic alkalosis but differs from Bartter syndrome by hypomagnesemia and hypocalciuria [3]. The basolateral potassium channel (KCNJ10) is the cause of the EAST syndrome (Epilepsy, Ataxia, Sensorineural deafness, and Tubulopathy) that also displays a phenotype closer from Gitelman syndrome than from Bartter syndrome [9]. The chronic use of furosemide that blocks the NKCC2 leads to an acquired biological phenotype of Bartter syndrome [10]. Nephrotoxic agents (aminoglycosides, amphotericin $\mathrm{B}$, and heavy metal intoxication) have also been reported to be sometime associated with a phenotype of Bartter syndrome [11-13]. Extrarenal loss of sodium chloride by the gastrointestinal tract (congenital chloride diarrhea) or by the skin (cystic fibrosis) may also display a biological phenotype of Bartter syndrome but these patients that have a normal renal tubular function differed from true Bartter syndrome by a very low excretion fraction of sodium $[14,15]$.

2.1. Urinary Sodium Wasting. Assuming a glomerular filtration rate of $100 \mathrm{~mL} / \mathrm{min}$ and a serum sodium concentration of $140 \mathrm{mmol} / \mathrm{L}$, about $20 \mathrm{~mol} /$ day of sodium are filtered everyday, equivalent to the amount of $1.2 \mathrm{~kg}$ of salt. Under physiological conditions, renal tubules are capable of reabsorbing 99 to $100 \%$ of filtered sodium and water. The primary consequence of a defect in the Henle loop is a failure to reabsorb $30 \%$ of the filtered sodium. The massive amount of sodium that is delivered downstream to the end of the Henle loop exceeds the possibility of compensation by the distal convoluted tubule and the collecting duct and leads to urinary sodium wasting [3].

2.2. Urinary Concentration and Dilution Defect. A second consequence of the defect of Henle loop is the abolition of the corticopapillary osmolar gradient that prevents the ability to concentrate the final urine over the plasma osmolality. In addition, patients display a partial impairment in diluting urine far below the plasma osmolality while half of the capacity of diluting urine is due to the anhydrous reabsorption of sodium chloride in the Henle loop, and the second half is due to the anhydrous reabsorption of sodium chloride in the distal convoluted tubule [16].

2.3. Hypercalciuria. Urinary calcium wasting is due to the abolition of the transtubular potential, the subsequent inability to passively drive divalent cations through the intercellular space in the Henle loop (see Figure 2) and the patent failure of downstream adaptation. The chronic loss of calcium is frequently responsible for an increased bone resorption and a decrease of bone mineralization that is proportional to the level of urine calcium [17]. Calcium supplementation may prevent these bone alterations.

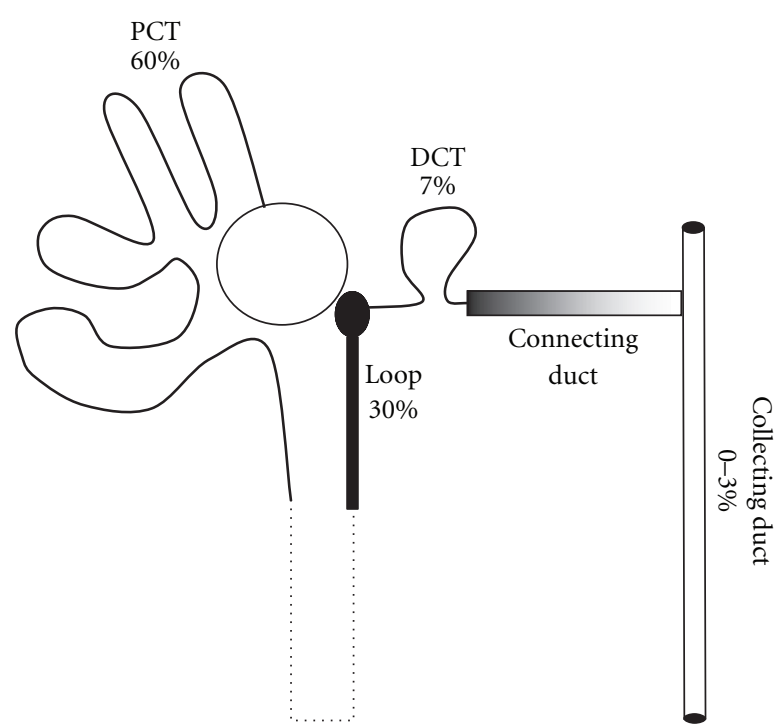

FIgURE 1: Segmentation of sodium reabsorption. Sodium reabsorption in tubular epithelial cells proceeds along a general two-step mechanism that includes a/an active extrusion of intracellular sodium ions by the basolateral sodium pump that is common to all tubular segments, b/ a passive apical entry of sodium dissipating the electrochemical gradient generated by the sodium pump via an exchanger or a cotransporter or a sodium channel that is specific to each tubular segment. Briefly, $175 \mathrm{~L} / 1.73 \mathrm{~m}^{2}$ of plasma roughly containing 20 moles of sodium chloride are filtered every day by the glomeruli, and 99 to $100 \%$ of this amount is reabsorbed in the convoluted and straight tubules (60\%), the thick ascending limb of the Henle loop (30\%), the distal convoluted tubule (7\%), the connecting and the collecting duct ( 0 to $3 \%$, controlled by aldosterone and angiotensin-2). The thin descending and ascending limbs of the Henle loop do not display any capacities to reabsorb sodium. Proximal tubular failure leads to the Fanconi syndrome where sodium wasting is associated with numerous solute wasting (potassium, bicarbonates, calcium, phosphates, glucose, aminoacids). Failure of the large ascending limb of the Henle loop is responsible for the Bartter syndrome, of the distal convoluted tubule for the Gitelman syndrome, and of the collecting duct for type 1 Pseudohypoaldosteronism [3].

\section{Secondary Biological Adaptations}

3.1. Hyperreninism. The extracellular volume is a sodium salt solution that is closely maintained to a steady-state osmolality of $300 \mathrm{mosmol} / \mathrm{Kg}$. Chronic sodium depletion subsequently leads to a contraction of the extracellular volume. Hypotension, failure to thrive, and at the biological level, either an increased concentration of the total plasma protides or a high hematocrit are the common signs of extracellular volume contraction $[19,20]$. Chronic hypovolemia results in a stimulation of the renin axis and enhances the production of angiotensin-2 that stimulates the sodium reabsorption in the principal cell of the collecting duct (Figure 3) [21].

3.2. Hyperaldosteronism. Angiotensin-2 directly increases the secretion of aldosterone by the granulosa of the adrenal glands [22]. Aldosterone adds to the stimulation of the 


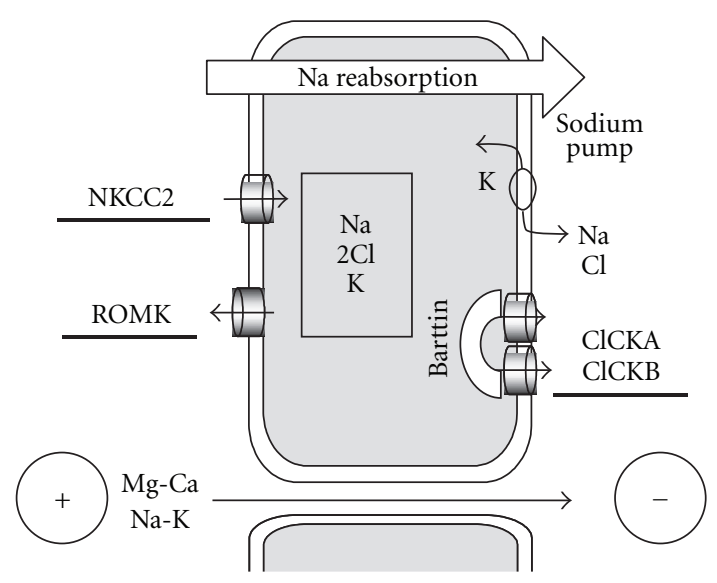

Figure 2: Structures involved in sodium reabsorption in the Henle loop. The large part of the Henle loop is mainly dedicated to sodium reabsorption. The system is vectorized and energized by the sodium pump at the basolateral face of the cell. KCNJ10 (not drawn on the figure) is supposed to recycle potassium at the basolateral face of the cell allowing fueling of the sodium pump in extracellular potassium. At the apical face, the sodium is cotransported with 1 potassium and 2 chlorides by the NKCC 2 cotransporter. The four sites of the NKCC2 have to be occupied to generate an electroneutral transport. As the urinary fluid is 30 -fold more concentrated in sodium than in potassium, potassium ions are recycled in the urine fluid at the luminal face of the cell through the ROMK (rectified outer medullary potassium) channel, in order to provide enough potassium for a continuous activity of the NKCC2. The 2 chlorides are reabsorbed at the basolateral face of the cell by the chloride channels CLCKA and B. Those channels need to be addressed and clustered at the basolateral membrane by the barttin. The main regulator of sodium reabsorption in the Henle loop is the vasopressin (also referred as antidiuretic hormone). The asymmetry of charges in the lumen (excess of potassium) and in the interstitium (excess of chloride) generates a potential according to the $3^{\text {rd }}$ principle of thermodynamics (Nernst formula). The paracellular transport of cations (calcium and magnesium as well as sodium and potassium in some extent) through the intercellular space is allowed by special claudins (claudines16 and 19, also referred as paracellins) and dissipates the transepithelial potential of the Henle loop [2, 3].

sodium reabsorption in the collecting duct and also likely stimulates those in the distal convoluted tubule [23]. Hyperaldosteronism may be dampened, relatively to a high renin stimulation, by hypokalemia and potassium depletion that directly interfere with aldosterone secretion in the granulosa [22].

3.3. Hypokalemia. As in any case of hyperaldosteronism, the exacerbation of the sodium reabsorption is closely associated to an exacerbation of the potassium secretion due to the stimulation of the crossed transport activity of sodium and potassium by the sodium pump. Consistently, hyperaldosteronism and urinary potassium wasting improve when sodium supplementation is increased [24]. Conversely, hypokalaemia and potassium depletion may improve with angioconvertase inhibitors, likely through a decrease of production of angiotensin- 2 and the deactivation of the collecting duct [25]. Accordingly, patients treated with enalapril had a fall in blood pressure and a decrease in glomerular filtration rate [25].

3.4. Alkalosis. The mechanism of alkalosis might be explained by an effect of aldosterone on the expression of the proton ATPase located in the $\alpha$-intercalated cell but, $\alpha$-intercalated cell does not express the mineralocorticoid receptor $[26,27]$. A second possibility is that the potassium depletion might be responsible for a de novo expression of the gastric proton-potassium ATPase (sensitive to omeprazole) at the luminal face of the principal cell in order to reabsorb a part of the secreted potassium. For each potassium ion that is internalized, 1 hydrogen is extruded in the urine by the proton potassium ATPase, generating alkalosis [18, 28]. This adaptation that has been fully demonstrated in rat models of potassium depletion might also apply to humans.

3.5. Complications of Potassium Depletion. Hypokalemic periodic paralysis and rhabdomyolysis has been reported for hypokalaemia below $2 \mathrm{mmol} / \mathrm{L}$ and fully resolved following the reload of the system with potassium chloride $[29,30]$. Prolonged QT interval has been evidenced with hypokalemia below $2 \mathrm{mmol} / \mathrm{L}$, and subsequent aborted sudden cardiac death may occur [31, 32]. Potassium depletion also induces coronary microvascular and myocardial defects during exercise in patients with Bartter syndrome [33].

3.6. Polyuria. The mechanism of polyuria in Bartter syndrome has to be considered differently in the antenatal period and after birth. In the antenatal period, the final urine delivered by a normal fetus is hypoosmolar suggesting that the water reabsorption in the collecting duct is not yet matured before birth while the anhydrous reabsorption of sodium chloride is fully functional in the Henle loop $[34,35]$. In the amniotic fluid, the fetal urine is balanced with the fetal plasma that circulates in the fetal membranes (amnion and chorion) [34]. In physiological conditions, the difference of the osmotic pressure between the amniotic fluid and the fetal plasma strongly favors a water outflow from the amniotic fluid into the capillaries of the fetal membranes [36]. Indeed, 5 types of aquaporins (AQP-1, -3, -4, -8, -9) are strongly expressed in the amnion and the chorion [37]. In fetus with Bartter syndrome, the amniotic fluid is fed with the fetal urine that is released at the end of the proximal convoluted tubule and not modified in the Henle loop. In these conditions, the fetal urinary osmolality is equal to those of the fetal plasma, likely preventing any water transfer from the amniotic fluid into the fetal plasma and leading to a polyhydramnios. The concentration of solutes remains balanced in the amniotic fluid while the total protein concentration (the solid phase) is diluted [38]. After birth, the polyuria is supposed to be generated by the addition of the inability of the kidneys to concentrate the final urine over the plasma osmolality and the increase of excreted osmoles due to the urinary sodium and potassium wasting. 


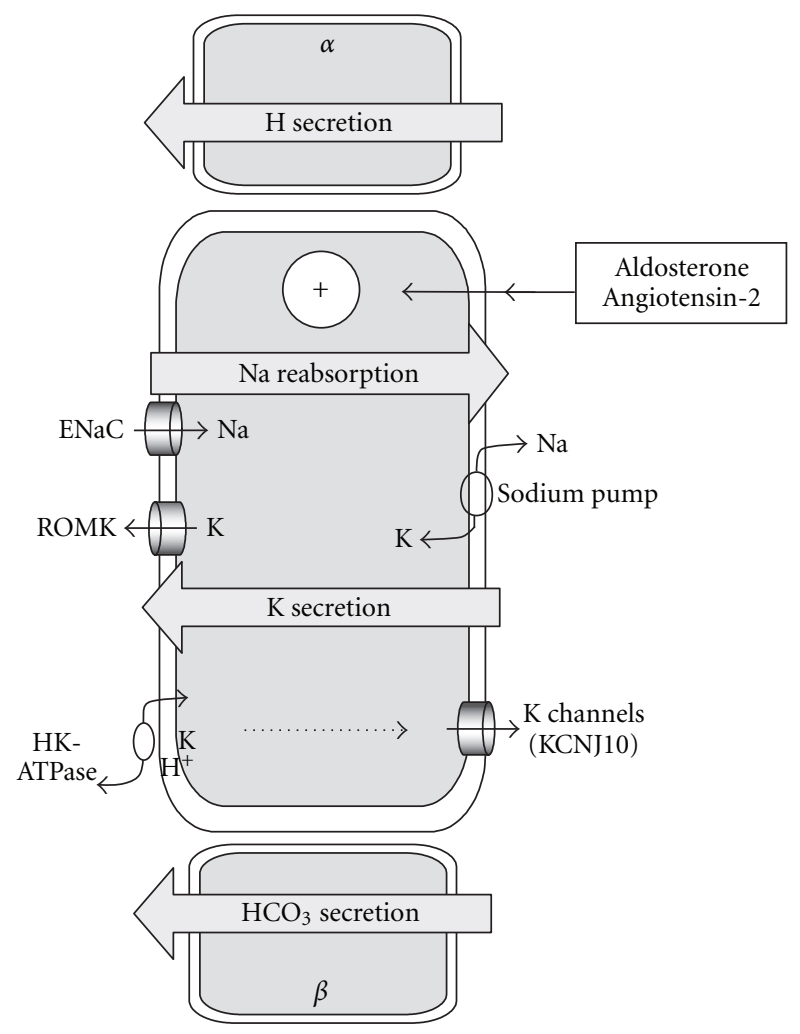

FIGURE 3: Activation of the principal cell of the collecting duct by aldosterone and angiotensin-2. The collecting duct is a composite structure made of 3 types of cells: the principal cell that assumes sodium and water reabsorption and potassium secretion, the $\alpha$-intercalated cell dedicated to hydrogen secretion, and the $\beta$-intercalated cell dedicated to bicarbonate secretion. In the principal cell, the reabsorption of sodium is vectorized through the epithelial sodium channel at the apical side of the principal cell and the sodium pump at the basolateral side. Potassium ions are cross-transported against sodium ions by the sodium pump and secreted in the lumen by the ROMK channel that is the same ROMK channel expressed in the Henle loop. Chronic sodium depletion and the subsequent extracellular volume contraction lead to an activation of the renin-angiotensin2-aldosterone axis that leads to the enhancement of sodium reabsorption and an exacerbated crosssecretion of potassium by the principal cell. The subsequent potassium depletion leads to hypokalemia and likely induces the expression of the gastric proton-potassium pump (inhibited by omeprazole) at the apical face of the principal cell leading to an excessive secretion of hydrogen and a subsequent alkalosis [18].

3.7. Hyperprostaglandinuria. Hyperprostaglandinuria is not specific of Bartter syndrome and has been either reported in sodium depletion without Bartter syndrome $[39,40]$ or in water deprivation [41-43]. Tissular secretion of $\mathrm{PGE}_{2}$ is stimulated by the vasopressin [44] either secondary to hypovolemia due to a sodium depletion or hypernatremia. In the kidney, cyclooxygenase-1 (COX1) is highly expressed in the collecting duct, and cyclooxygenase-2 (COX2) is expressed predominantly in the renal medullary interstitial cells, in the cortical thick ascending limb and in the cells associated with the macula densa. In addition, prostaglandin E synthase (PGES1) is highly expressed in the collecting duct and also detected in the thick ascending limb and the macula densa [45].

\section{Specificities according to the Molecular Defect.}

4.1. SLC12A1 (NKCC2). Mutations of SLC12A1 gene have been associated with the most typical form of antenatal Bartter syndrome featuring early onset of polyhydramnios, neonatal polyuria, and dehydration requiring massive amount of water and sodium supplementation in the first days of life, detectable nephrocalcinosis on renal ultrasound within the first month, and high plasma level of renin and secondary hypokalemic alkalosis following the first days of life [46, 47]. A delayed onset in life has also been exceptionally reported in cases with a residual function of the NKCC2 cotransporter [48].

4.2. $R O M K$ (KCNJ1). Mutations in the KCNJ1 gene display the same clinical phenotype as described in the NKCC2 section, but transient hyperkalemia and acidosis are observed during the first month of life $[46,47,49]$. Kalemia secondarily decreases along the course of the disease, but hypokalemia frequently failed to develop in these patients [47, 49]. A delayed onset in life has also been exceptionally reported in cases with a residual function of the ROMK channel [50].

4.3. $C l C K-b$ (CLCNKB). Mutations in the CLCNKB gene give the most variable clinical phenotypes from early polyhydramnios and severe neonatal polyuria $[46,47]$ to classic 
Bartter syndrome with a delayed diagnosis in childhood and failure to thrive [51] and to the phenotype of Gitelman syndrome without polyuria [52]. Hypercalciuria may lack in some patients with CLCNKB mutations [46].

4.4. Barttin (BSND). Barttin mutations are marked by deafness [53]. Most of the patients have a severe tubular disease, but a few adults have been recognized on deafness with a mild renal phenotype [54]. Hypercalciuria may also lack in a set of patients with BNSD mutations [46].

\section{Treatment}

Undelayed management of neonates with fully symptomatic antenatal Bartter syndrome is a necessity. Prenatal diagnosis relies on the occurrence of polyhydramnios without any classical cause of polyhydramnios (mainly maternal diabetes and fetal gastrointestinal tract malformation). The analysis of sodium, potassium, and chloride concentration relatively to those of total protein and alphafetoprotein in the amniotic fluid (the Bartter Index) is a reliable tool to confirm the diagnosis when familial history is lacking [38].

5.1. Sodium Chloride and Water. According to the physiopathology of the disease, the primary treatment of Bartter syndrome, at least in the neonatal period and in childhood, is the supplementation in sodium chloride. Data are scarce but some reports show that the amounts of sodium chloride needed to balance the extracellular volume, and prevent dehydration and hypovolemia to limit the stimulation of the renin axis, may reach $50 \mathrm{mmol} / \mathrm{Kg} /$ day in neonates $[46,55,56]$. Polyuria may occur immediately after birth prior to any sodium supplementation and requires water inputs that have sometimes to be rapidly increased up to $500 \mathrm{~mL} / \mathrm{Kg} /$ day within the first days of life $[55,56]$. Secondarily, continuous supplementation with water and sodium chloride either through a nasogastric tube or a gastrostomy may be necessary to improve growth in weight and length during the first months or years of life [57, 58]. A free access to sodium chloride and water when children gain food autonomy is as much as important that a free access to water for the children that are affected with a nephrogenic diabetes insipidus. Intravenous infusions of sodium salt solutions are necessary to prevent life-threatening dehydration in case of vomiting or diarrhea.

5.2. Potassium Chloride. Sodium chloride supplementation should be the best way to preserve children from hypokalemia and potassium depletion through the control of the extracellular volume and the renin-aldosterone axis. [59] Nevertheless, in some patients, the amounts of sodium chloride that would balance the extracellular volume and the renin system are so elevated that they are not acceptable by the patient. A potassium-rich diet and potassium chloride supplementation are subsequently needed.

5.3. Indomethacin. Indometacin has been used either prior to birth to prevent the recurrence of a polyhydramnios or after birth to limit the polyuria $[60,61]$. In the fetus with a Bartter syndrome, the amount of urine that is delivered at the end of the proximal convoluted tubule is directly proportional to the glomerular filtration rate. Therefore, the effect of indomethacin in preventing the recurrence of polyhydramnios following a drain is likely due to its action on glomerular vasculature, the reduction of the fetal glomerular filtration rate, and the subsequent reduction of fetal urine output [62]. After birth, prostaglandins are paradoxically potent inhibitors of the sodium reabsorption in the collecting duct through their specific receptor $\mathrm{EP}_{1}$ and $\mathrm{EP}_{2}[45,63]$. In addition, inhibition of prostaglandin synthesis during fasting in healthy man increases renal sodium absorption through a possible direct regulation of the epithelial sodium channels [64]. In the same time, prostaglandins are likely to be responsible for a decrease of the expression of aquaporin- 2 and the $V_{2}$ receptor resulting in a decrease of water permeability in the collecting duct [65] that is supposed to amplify the polyuria. Therefore, the beneficial effect of indomethacin on urinary sodium wasting and polyuria might be better figured out by the inhibition of the prostaglandins pathway on tubular structures than by a mild or a moderate decrease of the glomerular filtration rate $[66,67]$. However, prescribers must be aware that necrotizing enterocolitis and death have been reported following the use of indomethacin in the neonatal period [55, 58, 68-70].

5.4. Potassium-Sparing Drugs. Many drugs are susceptible to block the secretion of potassium in the collecting duct and to prevent potassium depletion. Those that have been used in Bartter syndrome are modamide, the antagonist of the Epithelial Sodium Channel, spironolactone, the antagonist of mineralocorticoid receptor, and angiotensin-converting enzyme inhibitors. Unfortunately, all these drugs impair the stimulation of the sodium reabsorption in the collecting duct and are susceptible to worsen the urinary sodium wasting and the chronic contraction of the extracellular volume $[25,71,72]$.

\section{Unresolved and New Questions}

6.1. Cysts. The development of renal cysts have been reported in patients with Bartter syndrome, of whom one had a mutation in the CLCNKB gene $[61,73]$. The mechanism remains unveiled.

6.2. Chronic Renal Failure. Renal fibrosis has been reported in a series of 12 patients, of whom four had a decreased glomerular filtration rate. No statistical correlations could be established between the indomethacin dose and the percentage of altered interstitial surface area [74]. By contrast, significant relationships have been evidenced between the severity of urinary sodium wasting and the level of the glomerular filtration rate suggesting that the extent of renal fibrosis might be related to the chronic contraction of the extracellular volume and hypovolemia. Consistently, the development of chronic renal failure is a frequent feature in patients with a barttin mutation in parallel to severe chronic 
extracellular dehydration $[53,75]$. In addition, chronic renal failure has also reported in patients who developed proteinuria and lesions of focal segmental glomerulosclerosis superimposed to a Bartter syndrome [76, 77]. Finally, end stage renal failure is rare but has been yet reported [78].

6.3. Secondary Diabetes Insipidus. Hypernatremia with spontaneous diluted urine below $100 \mathrm{mosmol} / \mathrm{Kg}$ and failure to concentrate urine over $200 \mathrm{mosmol} / \mathrm{Kg}$ has been reported without any mutation in the genes of the $V_{2}$ receptor and aquaporine-2 [57]. Diluted final urine may be paradoxical in Bartter syndrome while the Henle loop is a major site to dilute urine. One should recall that the first half of the distal convolution is also water impermeable while aquaporine-2 is never coexpressed along with the sodiumchloride transporter [79] and that the distal convolution may consequently account for by a nonnegligible part of the diluting urine capacity [80]. Nevertheless, the failure of the principal cell of the collecting duct to appropriately transport water when strongly and continuously activated by angiotensin-2 and aldosterone remains to be understood.

6.4. Cholelithiasis. A case of cholelithiasis has been reported recently and attributed to alkalosis and dehydration that favour precipitation of calcium carbonate in biliary ducts [81].

\section{Conclusion}

In conclusion, renal physiology allows a rational approach to understand the biological features of Bartter syndrome and supports sodium chloride supplementation as the most appropriate treatment to control both the extracellular volume and the potassium depletion. On a basic point of view, it is noteworthy that the preservation of the sodium pool (and the balance of the extracellular volume) is a higher priority of the system than the protection against the potassium depletion, itself a priority upon the hydrogen balance.

\section{References}

[1] Frederic, C. Bartter, Mix, P. Pronove, J. R. Gill, and R. C. MacCardi, "Hyperplasia of the juxtaglomerular complex with hyperaldosteronism and hypokalemic alkalosis a new syndrome," Journal of the American Society of Nephrology, vol. 9, no. 3, pp. 516-528, 1998.

[2] F. Morel and A. Doucet, "Functional segmentation of the nephron. Dans: the kidney: physiology and pathophysiology," Raven Press, pp. 1049-1086, 1972.

[3] R. Kleta and D. Bockenhauer, "Bartter syndromes and other salt-losing tubulopathies," Nephron - Physiology, vol. 104, no. 2, pp. p73-p80, 2006.

[4] K. Nozu, T. Inagaki, X. J. Fu et al., "Molecular analysis of digenic inheritance in Bartter syndrome with sensorineural deafness," Journal of Medical Genetics, vol. 45, no. 3, pp. 182186, 2008.

[5] K. P. Schlingmann, M. Konrad, N. Jeck et al., "Salt Wasting and Deafness Resulting from Mutations in Two Chloride Channels," New England Journal of Medicine, vol. 350, no. 13, pp. 1314-1319, 2004.
[6] R. Vargas-Poussou, C. Huang, P. Hulin et al., "Functional characterization of a calcium-sensing receptor mutation in severe autosomal dominant hypocalcemia with a Bartter-like syndrome," Journal of the American Society of Nephrology, vol. 13, no. 9, pp. 2259-2266, 2002.

[7] R. Bogdanović, M. Draaken, A. Toromanović, M. Crossed Dević, N. Stajić, and M. Ludwig, "A novel CLCN5 mutation in a boy with Bartter-like syndrome and partial growth hormone deficiency," Pediatric Nephrology, vol. 25, no. 11, pp. 23632368, 2010.

[8] A. Çaltik, S. G. Akyz, Ö. Erdogan, M. Bülbül, and G. Demircin, "Rare presentation of cystinosis mimicking bartter's syndrome: reports of two patients and review of the literature," Renal Failure, vol. 32, no. 2, pp. 277-280, 2010.

[9] D. Bockenhauer, S. Feather, H. C. Stanescu et al., "Epilepsy, ataxia, sensorineural deafness, tubulopathy, and KCNJ10 mutations," New England Journal of Medicine, vol. 360, no. 19, pp. 1960-1970, 2009.

[10] A. Numabe, A. Ogata, M. Abe et al., "A case of pseudo-Bartter's syndrome induced by long-term ingestion of furosemide delivered orally through health tea," Japanese Journal of Nephrology, vol. 45, no. 5, pp. 457-463, 2003.

[11] A. Chrispal, H. Boorugu, A. T. Prabhakar, and V. Moses, "Amikacin-induced type 5 Bartter-like syndrome with severe hypocalcemia," Journal of Postgraduate Medicine, vol. 55, no. 3, pp. 208-210, 2009.

[12] W. J. Crinnion and J. Q. Tran, "Case report: heavy metal burden presenting as Bartter syndrome," Alternative medicine review, vol. 15, no. 4, pp. 303-310, 2010.

[13] J. B. López Sastre, G. D. Coto Cotallo, and B. Fernández Colomer, "Neonatal invasive candidiasis: a prospective multicenter study of 118 cases," American Journal of Perinatology, vol. 20, no. 3, pp. 153-163, 2003.

[14] U. Ozcelik, A. Gocmen, N. Kiper, T. Coskun, E. Yilmaz, and M. Ozguc, "Sodium chloride deficiency in cystic fibrosis patients," European Journal of Pediatrics, vol. 153, no. 11, pp. 829-831, 1994.

[15] J. Kere, H. Lohi, and P. Höglund, "Genetic disorders of membrane transport. III. Congenital chloride diarrhea," American Journal of Physiology, vol. 276, no. 1, pp. G7-G13, 1999.

[16] J. M. Sands and H. E. Layton, "The Physiology of urinary concentration: an update," Seminars in Nephrology, vol. 29, no. 3, pp. 178-195, 2009.

[17] J. Rodríguez-Soriano, A. Vallo, and M. Aguirre, "Bone mineral density and bone turnover in patients with Bartter syndrome," Pediatric Nephrology, vol. 20, no. 8, pp. 1120-1125, 2005.

[18] N. Laroche-Joubert and A. Doucet, "Collecting duct adaptation to potassium depletion," Seminars in Nephrology, vol. 19, no. 5, pp. 390-398, 1999.

[19] A. N. Lasaridis, B. Pitsariotis, C. Syrganis, C. Gatzis, E. Brettou, and A. Tourkantonis, "Severe orthostatic hypotension due to Bartter's syndrome," Clinical Nephrology, vol. 28, no. 2, pp. 105-106, 1987.

[20] D. Allapathi, D. Alvarez, S. Dave-Sharma, G. Prosper, and J. Sharma, "Severe failure to thrive in infant," Clinical Pediatrics, vol. 47, no. 7, pp. 698-700, 2008.

[21] K. T. Beutler, S. Masilamani, S. Turban et al., "Long-term regulation of $\mathrm{ENaC}$ expression in kidney by angiotensin II," Hypertension, vol. 41, no. 5, pp. 1143-1150, 2003.

[22] J. M. C. Connell and E. Davies, "The new biology of aldosterone," Journal of Endocrinology, vol. 186, no. 1, pp. 1-20, 2005.

[23] M. Vinciguerra, D. Mordasini, A. Vandewalle, and E. Feraille, "Hormonal and nonhormonal mechanisms of regulation of 
the Na,K-pump in collecting duct principal cells," Seminars in Nephrology, vol. 25, no. 5, pp. 312-321, 2005.

[24] M. Fulop, "A patient with sodium- and potassium-losing nephropathy," American Journal of the Medical Sciences, vol. 325, no. 2, pp. 93-97, 2003.

[25] R. J. Hene, H. A. Koomans, and E. J. Dorhout Mees, "Correction of hypokalemia in Bartter's syndrome by enalapril," American Journal of Kidney Diseases, vol. 9, no. 3, pp. 200-205, 1987.

[26] C. Winter, N. Schulz, G. Giebisch, J. P. Geibel, and C. A. Wagner, "Nongenomic stimulation of valcuolar H+-ATPases in intercalated renal tubule cells by aldosterone," Proceedings of the National Academy of Sciences of the United States of America, vol. 101, no. 8, pp. 2636-2641, 2004.

[27] A. Náray-Fejes-Tóth, E. Rusvai, and G. Fejes-Tóth, "Minealocorticoid receptors and 11 beta-steroid dehydrogenase activity in renal principal and intercalated cells," American Journal of Physiology, vol. 266, pp. F76-F80, 1994.

[28] N. Laroche-Joubert, S. Marsy, and A. Doucet, "Cellular origin and hormonal regulation of $\mathrm{K}+$-ATPase activities sensitive to Sch-28080 in rat collecting duct," American Journal of Physiology - Renal Physiology, vol. 279, no. 6, pp. F1053-F1059, 2000.

[29] O Duman, M. Koyun, S. Akman, A. G. Güven, and S. Haspolat, "Case of Bartter syndrome presenting with hypokalemic periodic paralysis," Journal of Child Neurology, vol. 21, no. 3, pp. 255-256, 2006.

[30] R. O. Von Vigier, M. T. Ortisi, A. La Manna, M. G. Bianchetti, and A. Bettinelli, "Hypokalemic rhabdomyolysis in congenital tubular disorders: a case series and a systematic review," Pediatric Nephrology, vol. 25, no. 5, pp. 861-866, 2010.

[31] C. Cortesi, S. A. G. Lava, A. Bettinelli et al., "Cardiac arrhythmias and rhabdomyolysis in Bartter-Gitelman patients," Pediatric Nephrology, vol. 25, no. 10, pp. 2005-2008, 2010.

[32] R. Scognamiglio, C. Negut, and L. A. Calò, "Aborted sudden cardiac death in two patients with Bartter's/Gitelman's syndromes," Clinical Nephrology, vol. 67, no. 3, pp. 193-197, 2007.

[33] R. Scognamiglio, L. A. Calò, C. Negut, M. Coccato, P. Mormino, and A. C. Pessina, "Myocardial perfusion defects in Bartter and Gitelman syndromes," European Journal of Clinical Investigation, vol. 38, no. 12, pp. 888-895, 2008.

[34] D. Anderson, Q. Yang, A. Hohimer, J. Faber, G. Giraud, and L. Davis, "Intramembranous absorption rate is unaffected by changes in amniotic fluid composition," American Journal of Physiology - Renal Physiology, vol. 288, no. 5, pp. F964-F968, 2005.

[35] M. G. Coulthard and E. N. Hey, "Effect of varying water intake on renal functionin healthy preterm babies," Archives of Disease in Childhood, vol. 60, no. 7, pp. 614-620, 1985.

[36] J. J. Faber and D. F. Anderson, "Absorption of amniotic fluid by amniochorion in sheep," American Journal of Physiology Heart and Circulatory Physiology, vol. 282, no. 3, pp. H850H854, 2002.

[37] A. E. Damiano, "Review: water channel proteins in the human placenta and fetal membranes," Placenta, 2011.

[38] A. Garnier, S. Dreux, R. Vargas-Poussou et al., "Bartter syndrome prenatal diagnosis based on amniotic fluid biochemical analysis," Pediatric Research, vol. 67, no. 3, pp. 300-303, 2010.

[39] H. Nivet, B. Grenier, and J. C. Rolland, "Raised urinary prostaglandins in patient without Bartter's syndrome," Lancet, vol. 1, no. 8059, pp. 333-334, 1978.

[40] E. Mayatepek, H. W. Seyberth, and W. Nutzenadel, "Effects of indomethacin in congenital chloride diarrhea," Journal of Pediatric Gastroenterology and Nutrition, vol. 14, no. 3, pp. 319-322, 1992.
[41] A. Zucker, A. Nasjletti, and E. G. Schneider, "Effect of water deprivation on urinary excretion of PGE2 in the dog," American Journal of Physiology, vol. 14, no. 3, pp. R329-R333, 1983.

[42] M. Sugawara, K. Hashimoto, and Z. Ota, "Involvement of prostaglandin E2, cAMP, and vasopressin in lithium-induced polyuria," American Journal of Physiology, vol. 254, no. 6, p. 23/6, 1988.

[43] W. Rascher, W. Rosendahl, I. A. Henrichs, R. Maier, and H. W. Seyberth, "Congenital nephrogenic diabetes insipidus - vasopressin and prostaglandins in response to treatment with hydrochlorothiazide and indomethacin," PEDIATR. NEPHROL., vol. 1, no. 3, pp. 485-490, 1987.

[44] N. Bouby, M. M. Trinh Trang Tan, M. Doute, and L. Bankir, "Effects of osmolality and antidiuretic hormone on prostaglandin synthesis by renal papilla. Study in Brattleboro rats with diabetes insipidus," Pflugers Archiv European Journal of Physiology, vol. 400, no. 1, pp. 96-99, 1984.

[45] C. M. Hao and M. D. Breyer, "Physiological regulation of prostaglandins in the kidney," Annual Review of Physiology, vol. 70, pp. 357-377, 2008.

[46] K. Brochard, O. Boyer, A. Blanchard et al., "Phenotypegenotype correlation in antenatal and neonatal variants of Bartter syndrome," Nephrology Dialysis Transplantation, vol. 24, no. 5, pp. 1455-1464, 2009.

[47] R. Matz, N. Jeck, S. Reinalter et al., "Clinical presentation of genetically defined patients with hypokalemic salt-losing tubulopathies," American Journal of Medicine, vol. 112, no. 3, pp. 183-190, 2002.

[48] C. A. Pressler, J. Heinzinger, N. Jeck et al., "Late-onset manifestation of antenatal Bartter syndrome as a result of residual function of the mutated renal $\mathrm{Na}+-\mathrm{K}+-2 \mathrm{Cl}-\mathrm{co}-$ transporter," Journal of the American Society of Nephrology, vol. 17, no. 8, pp. 2136-2142, 2006.

[49] G. Finer, H. Shalev, O. S. Birk et al., "Transient neonatal hyperkalemia in the antenatal (ROMK defective) Bartter syndrome," Journal of Pediatrics, vol. 142, no. 3, pp. 318-323, 2003.

[50] A. Sharma and M. A. Linshaw, "A novel compound heterozygous ROMK mutation presenting as late onset Bartter syndrome associated with nephrocalcinosis and elevated 1,25(OH)2 vitamin D levels," Clinical and Experimental Nephrology, vol. 15, no. 4, pp. 572-576, 2011.

[51] M. Konrad, M. Vollmer, H. H. Lemmink et al., "Mutations in the chloride channel gene CLCNKB as a cause of classic Bartter syndrome," Journal of the American Society of Nephrology, vol. 11, no. 8, pp. 1449-1459, 2000.

[52] N. Jeck, M. Konrad, M. Peters, S. Weber, K. E. Bonzel, and H. W. Seyberth, "Mutations in the chloride channel gene, CLCNKB, leading to a mixed Bartter-Gitelman phenotype," Pediatric Research, vol. 48, no. 6, pp. 754-758, 2000.

[53] R. Birkenhäger, E. Otto, M. J. Schürmann et al., "Mutation of BSND causes Bartter syndrome with sensorineural deafness and kidney failure," Nature Genetics, vol. 29, no. 3, pp. 310314,2001

[54] S. Brum, J. Rueff, J. R. Santos Joao, and J. Calado, "Unusual adult-onset manifestation of an attenuated Bartter's syndrome type IV renal phenotype caused by a mutation in BSND [13]," Nephrology Dialysis Transplantation, vol. 22, no. 1, pp. 288289, 2007.

[55] G. Deschenes, A. Burguet, C. Guyot et al., "Antenatal form of Barter syndrome," Annales de Pediatrie, vol. 40, no. 2, pp. 95$101,1993$. 
[56] M. Kömhoff, I. Tekesin, M. Peters, A. Leonhard, and H. Seyberth, "Perinatal management of a preterm neonate affected by hyperprostaglandin E2 syndrome (HPS)," Acta Paediatrica, International Journal of Paediatrics, vol. 94, no. 11, pp. 16901693, 2005.

[57] D. Bockenhauer, W. Van’T Hoff, M. Dattani et al., "Secondary nephrogenic diabetes insipidus as a complication of inherited renal diseases," Nephron - Physiology, vol. 116, no. 4, pp. p23p29, 2010.

[58] W. Wong, S. A. Hulton, C. M. Taylor, F. Raafat, C. J. Lote, and G. Lindop, "A case of neonatal Bartter's syndrome," Pediatric Nephrology, vol. 10, no. 4, pp. 414-418, 1996.

[59] R. Kleta, C. Basoglu, and E. Kuwertz-Broking, "New treatment options for Bartter's syndrome [4]," New England Journal of Medicine, vol. 343, no. 9, pp. 661-662, 2000.

[60] M. D. Breyer and R. M. Breyer, "Prostaglandin E receptors and the kidney," American Journal of Physiology — Renal Physiology, vol. 279, no. 1 48-1, pp. F12-F23, 2000.

[61] M. H. Vaisbich, M. D. Fujimura, and V. H. Koch, "Bartter syndrome: benefits and side effects of long-term treatment," Pediatric Nephrology, vol. 19, no. 8, pp. 858-863, 2004.

[62] A. Drukker, "The adverse renal effects of prostaglandinsynthesis inhibition in the fetus and the newborn," Paediatrics and Child Health, vol. 7, no. 8, pp. 538-543, 2002.

[63] M. D. Breyer and R. M. Breyer, "Prostaglandin E receptors and the kidney," American Journal of Physiology - Renal Physiology, vol. 279, no. 1, pp. F12-F23, 2000.

[64] T. G. Lauridsen, H. Vase, J. Starklint et al., "Increased renal sodium absorption by inhibition of prostaglandin synthesis during fasting in healthy man. A possible role of the epithelial sodium channels," BMC Nephrology, vol. 11, no. 1, article no. 28, 2010.

[65] M. Boone and P. M. T. Deen, "Physiology and pathophysiology of the vasopressin-regulated renal water reabsorption," Pflugers Archiv European Journal of Physiology, vol. 456, no. 6, pp. 1005-1024, 2008.

[66] D. Shemin and L. D. Dworkin, "Sodium balance in renal failure," Current Opinion in Nephrology and Hypertension, vol. 6, no. 2, pp. 128-132, 1997.

[67] R. Ardaillou and J. C. Dussaule, "Role of atrial natriuretic peptide in the control of sodium balance in chronic renal failure," Nephron, vol. 66, no. 3, pp. 249-257, 1994.

[68] N. Marlow and M. L. Chiswick, "Neonatal Bartter's syndrome, indomethacin and necrotising enterocolitis," Acta Paediatrica Scandinavica, vol. 71, no. 6, pp. 1031-1032, 1982.

[69] M. Çetinkaya, N. Köksal, H. Özkan, O. Dönmez, H. Sağlam, and I. Kiriştioğlu, "Hyperprostaglandin E syndrome: use of indomethacin and steroid, and death due to necrotizing enterocolitis and sepsis," Turkish Journal of Pediatrics, vol. 50, no. 4, pp. 386-390, 2008.

[70] E. Ataoglu, M. Civilibal, A. A. Ozkul, I. G. Varal, E. R. Oktay, and E. Murat, "Indomethacin-induced colon perforation in Bartter's syndrome," Indian Journal of Pediatrics, vol. 76, no. 3, pp. 322-323, 2009.

[71] D. A. McCredie, E. Rotenberg, and A. L. Williams, "Hypercalciuria in potassium losing nephropathy: a variant of Bartter's syndrome," Australian Paediatric Journal, vol. 10, no. 5, pp. 286-295, 1974.

[72] E. Desmit, "Spironolactone therapy in hypokalæmia," The Lancet, vol. 277, no. 7183, p. 950, 1961.

[73] T. Watanabe and T. Tajima, "Renal cysts and nephrocalcinosis in a patient with Bartter syndrome type III," Pediatric Nephrology, vol. 20, no. 5, pp. 676-678, 2005.
[74] S. C. Reinalter, H. J. Gröne, M. Konrad, H. W. Seyberth, and G. Klaus, "Evaluation of long-term treatment with indomethacin in hereditary hypokalemic salt-losing tubulopathies," Journal of Pediatrics, vol. 139, no. 3, pp. 398-406, 2001.

[75] N. Jeck, S. C. Reinalter, T. Henne et al., "Hypokalemic saltlosing tubulopathy with chronic renal failure and sensorineural deafness," Pediatrics, vol. 108, no. 1, p. E5, 2001.

[76] H. Yamazaki, K. Nozu, I. Narita et al., "Atypical phenotype of type I Bartter syndrome accompanied by focal segmental glomerulosclerosis," Pediatric Nephrology, vol. 24, no. 2, pp. 415-418, 2009.

[77] I. H. Su, R. Frank, B. G. Gauthier et al., "Bartter syndrome and focal segmental glomerulosclerosis: a possible link between two diseases," Pediatric Nephrology, vol. 14, no. 10-11, pp. 970972, 2000.

[78] J. Y. Kim, G. A. Kim, J. H. Song et al., "A case of living-related kidney transplantation in Bartter's syndrome," Yonsei Medical Journal, vol. 41, no. 5, pp. 662-665, 2000.

[79] H. L. Biner, M. P. Arpin-Bott, J. Loffing et al., "Human cortical distal nephron: distribution of electrolyte and water transport pathways," Journal of the American Society of Nephrology, vol. 13, no. 4, pp. 836-847, 2002.

[80] W. I. Baba, A. F. Lant, and G. M. Wilson, "The action of oral diuretics in diabetes insipidus," Proceedings of the Royal Society of Medicine, vol. 58, no. 11, pp. 911-912, 1965.

[81] P. Robitaille, K. Tousignant, and J. Dubois, "Bartter syndrome and cholelithiasis in an infant: is this a mere coincidence?" European Journal of Pediatrics, vol. 167, no. 1, pp. 109-110, 2008. 


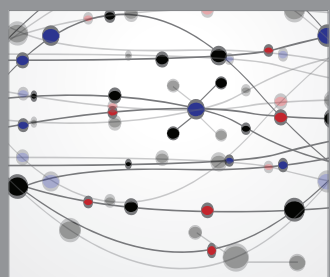

The Scientific World Journal
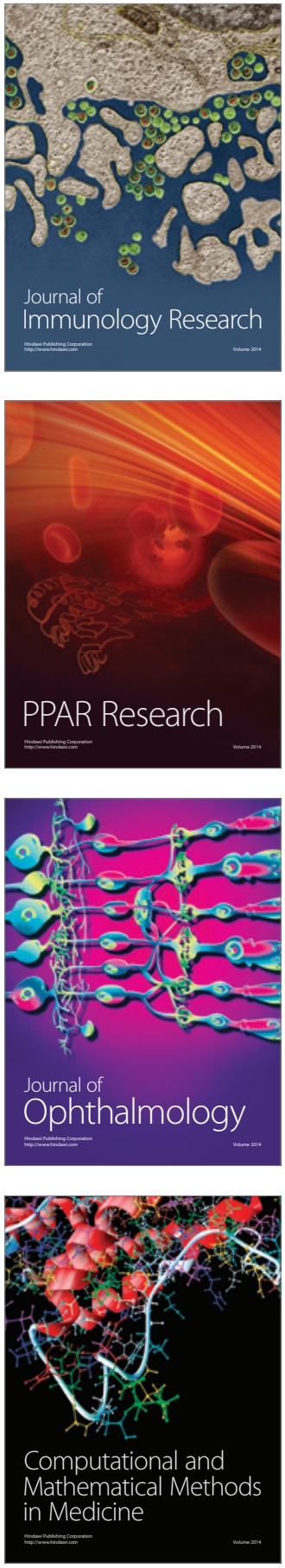

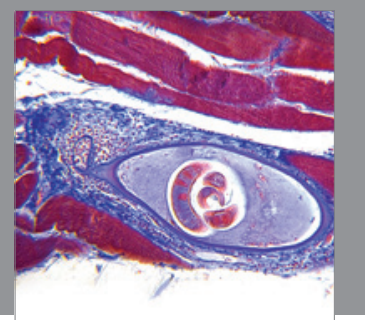

Gastroenterology

Research and Practice
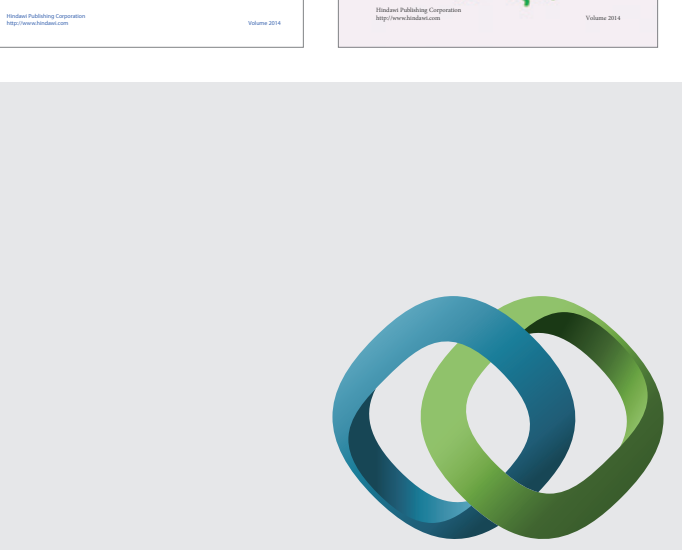

\section{Hindawi}

Submit your manuscripts at

http://www.hindawi.com
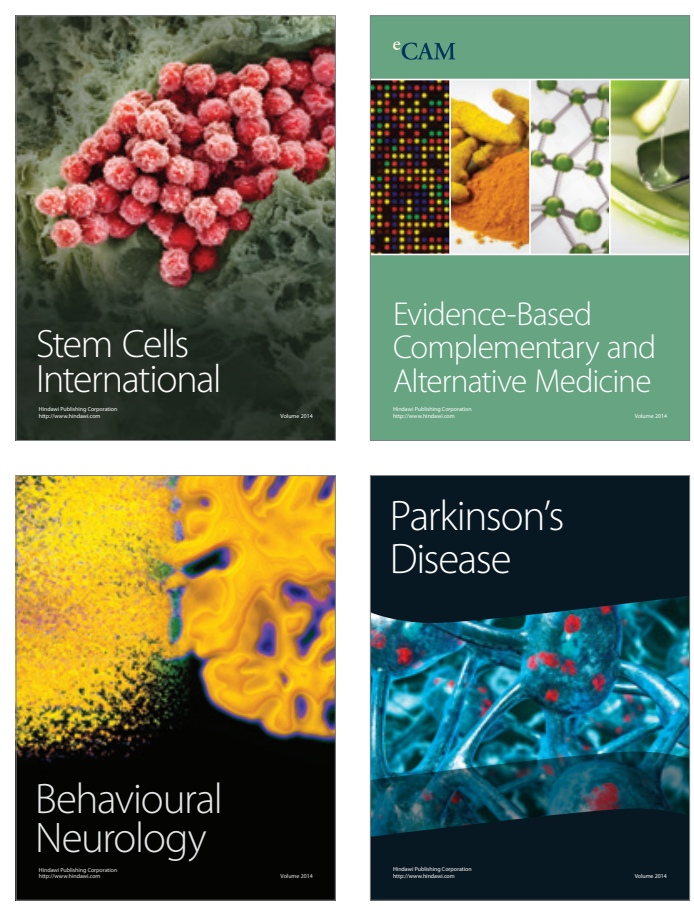

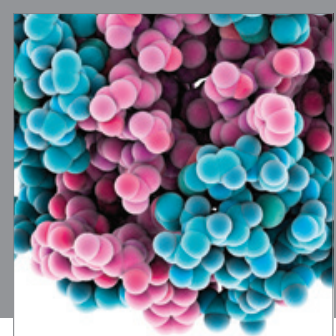

Journal of
Diabetes Research

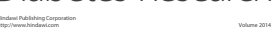

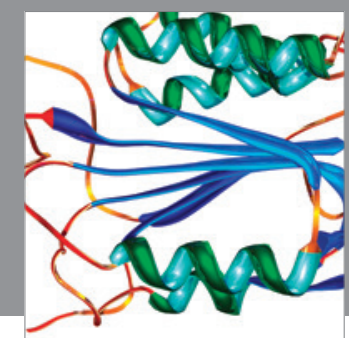

Disease Markers
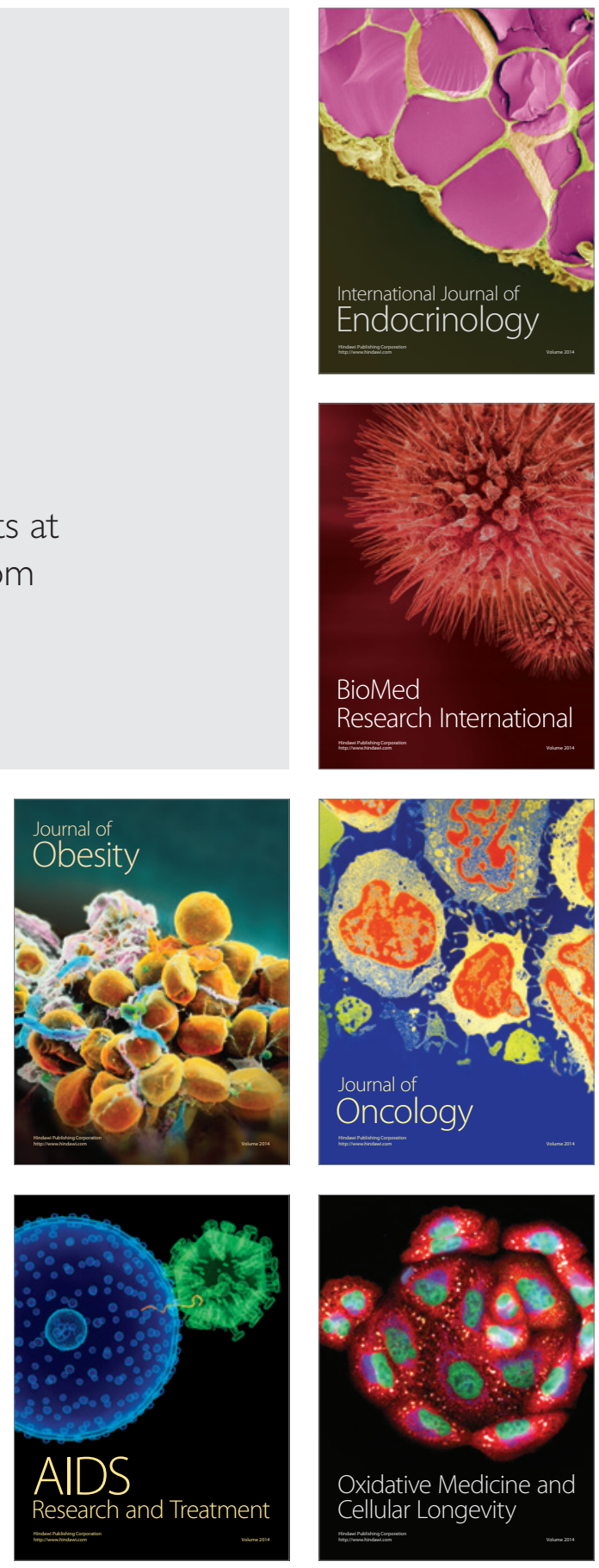